\title{
A RAINHA DO IGNOTO (1899), DE EMÍLIA FREITAS, UMA OBRA UTÓPICA
}

\author{
Elenara Walter Quinhones ${ }^{1}$
}

Resumo: a obra Utopia (1516), de Thomas More, inaugurou, no ocidente, o gênero literário utópico. Essa obra serviu de protótipo para diversos autores criarem ficcionalmente suas sociedades perfeitas. A partir dos anos 1970, as escritoras Joanna Russ, Marge Piercy, Margaret Atwood e Octavia E. Butler descobriram que desde os momentos iniciais da literatura de utopia, ela já vinha sendo utilizada como instrumento de crítica social por parte de diversas autoras. No Brasil, a autoria feminina do século XIX e início do século XX manteve-se em um processo de invisibilidade. Após o resgate historiográfico nacional encontrou-se a obra $A$ Rainha do Ignoto (1899), de Emília Freitas, que é delineada sob a proposição de um mundo novo. Esta pesquisa tem como objetivo discutir a obra de Freitas, tendo como ponto de partida que ela se insere na literatura utópica do romance ocidental, e analisar os imbricamentos políticos e históricos na obra, à luz dos conceitos de interdisciplinaridade e intertextualidade.

Palavras-chave: Autoria feminina. Utopia. A Rainha do Ignoto. Emília Freitas.

Abstract: the novel Utopia (1516), by Thomas More, opened in the west the utopian literary genre. This work served as the prototype for many authors fictionally create their perfect societies. From 1970 the women writers Joanna Russ, Marge Piercy, Margaret Atwood and Octavia E. Butler found that since the early moments of utopian literature it was already being used as an instrument of social criticism by various authors. In Brazil, the female authors of the nineteenth century and early twentieth century remained in a process of invisibility. After the national historiographical rescue met it the novel $A$ Rainha do Ignoto (1899), by Emilia Freitas, which is outlined under proposal of a new world. This research aims at discussing the work by Freitas having as starting point that it insert in the utopian literature of the western novel and analyze the political and historical imbrications in the novel according to the concepts of interdisciplinarity and intertextuality.

Keywords: Female authorship. Utopia. A Rainha do Ignoto. Emília Freitas.

\section{INTRODUÇÃO}

Desde os primórdios da História da humanidade, o homem procura criar um mundo perfeito, equânime, em que ideais políticos e sociais convirjam e

\footnotetext{
${ }^{1}$ Mestranda em Estudos Literários no Programa de Pós-Graduação em Letras pela UFSM. Bolsista CAPES. Orientador Prof. Dr. Anselmo Peres Alós. E-mail: elenaraquinhones@yahoo.com.br
} 
resultem no bem-estar da população, atingindo finalmente a paz. Para tanto, criaram-se os mitos e as religiões. Mais tarde, na Renascença a efervescência social e cultural com as descobertas marítimas propiciaram que o homem restringisse em uma única palavra essa busca pela perfeição social e política, surge assim à expressão "utopia". Ela provém da obra de Thomas More intitulada De optimo reipublicae statatu deque nova insula Utopia $(1516)^{2}$. Etimologicamente, "More cunhou-a ao fundir o advérbio grego ou - "não" - ao substantivo tópos - "lugar" - dando ao composto resultante uma terminação latina" (Logan, G.; Adams, R., 2009, p. XV). Utopia, de More, não reproduz ficcionalmente, apenas, uma república ideal, mas supõe-se que o autor cria também "uma sátira de uma má república" (Logan, G.; Adams, R., 2009, p. XVIII) como crítica ao momento histórico político da Inglaterra.

A obra de More inaugura "um novo gênero literário" (Logan, G.; Adams, R., 2009, p. XXVIII). Conforme Carlos Eduardo Ornelas Berriel, "as utopias literárias são essenciais para a compreensão do imaginário político moderno" (Berriel, 2012, p. 1). O autor afirma que "ao contrário da crença comum, a utopia não é, dominantemente, uma visão ficcional do futuro, e sim uma reflexão sobre o presente, considerando este como o complexo de graves problemas sociais e políticos que alarmam o ambiente cultural do utopista" (Berriel, 2012, p. 25).

Após a aparição da obra de Thomas More, surgiram muitas outras obras utópicas clássicas no decorrer do século XVI e XVII, como Cidade do Sol (1621), de Tommaso Campanella, e Nova Atlântida (1627), de Francis Bacon, entre outras (Berriel, 2012). Faz-se notório que, em muitas dessas obras, "o papel social da mulher é negligenciado seguindo um racionalismo eurocêntrico e masculino" (Silva, 2007, p. 2). Segundo Alexander Silva (2007), a partir dos anos 1970, as escritoras Joanna Russ, Marge Piercy, Margaret Atwood e Octavia E. Butler contestaram essas representações e descobriram que desde os momentos iniciais da literatura de utopia, ela já vinha sendo utilizada como instrumento de crítica social por parte de escritoras, como por exemplo, as obras The description of a new world, called The Blazing-World (1668), de

${ }^{2}$ Sobre a melhor constituição de uma República e a nova ilha Utopia. 
Margaret Cavendish, Herland (1915), de Charlotte Parkins Gilman e Swastika night (1937), de Katharine Burdekin.

No Brasil, a autoria feminina do século XIX e início do século XX manteve-se em um processo de invisibilidade. Segundo Constância Lima Duarte, "não se admitia à mulher qualquer iniciativa que the permitisse escapar do estreito círculo a que estava confinada. Os espartilhos do preconceito teimavam em mantê-la bem segura dentro dos limites do espaço doméstico" (Duarte, 1997, p. 56). Elas deveriam ficar longe do universo cultural, intelectual e político. Aos homens, além de seu inquestionável poder sobre a família, cabia domínio sobre o âmbito público. Conforme Duarte, "apesar de tudo e de todos, algumas superaram os obstáculos escrevendo e publicando, num flagrante desafio à ordem que as restringia à esfera privada" (Duarte, 1997, p. 57). Uma vez que esses obstáculos foram transpostos pelas autoras, faz-se necessário a manutenção do processo de revisão de nossa historiografia literária para resgatar obras de autoria feminina "pertinentemente esquecidas", e mobilizar as narrativas dessas autoras a fim de enriquecer nossa história literária. Nesse contexto, essa pesquisa objetiva discutir a obra $A$ Rainha do Ignoto, de Emília Freitas, e como o apagamento simbólico dessa obra influencia na história literária do país.

\section{A RAINHA DO IGNOTO, UMA UTOPIA?}

Publicada pela primeira vez em 1899, e reeditada apenas em 1980, pelo Professor Otacílio Colares, a obra $A$ Rainha do Ignoto só teve sua terceira edição em 2003, pela Editora Mulheres, organizada e atualizada pela Professora Constância Lima Duarte. O romance é construído em um sistema binário: desenvolvendo-se basicamente em dois espaços. Parte da trama desenrola-se no povoado Passagem das Pedras, e outra parte na cidade de Aracati, Ceará. Inicialmente, Passagem das Pedras é abalada com a chegada de Edmundo, jovem bacharel em Direito, que procura o lugar a fim de descansar de sua agitada vida social. Ali conhece Funesta, uma espécie de lenda local. Esta mulher navega, noturnamente, pelo Rio Jaguaribe. Ao ver-se totalmente envolvido no mistério de Funesta, Edmundo passa a investigá-la, 
até que conhece Probo, o caçador de onças, que lhe conta a história da misteriosa mulher.

Funesta é apenas um dos muitos disfarces da Rainha do Ignoto, que possui um reino secreto só acessível ao adentrar a gruta do Araré. Esse reino, denominado Ilha do Nevoeiro, se mantém escondido por indução hipnótica realizada pelas paladinas, mulheres recrutadas pela Rainha que exercem diferentes funções dentro da sociedade, fica localizado na costa brasileira. Edmundo adentra a comunidade feminina travestido de mulher, com a ajuda de Probo e Roberta ${ }^{3}$, esposa deste. Ele consegue permanecer três anos convivendo com a Rainha e conclui que ela é um ser a parte dos outros, por seus valores e qualidades incomuns. Finalmente, ele decide voltar para Passagem das Pedras e casa-se com Carlotinha, jovem apaixonada por ele desde o início da trama.

A Rainha, ao ver que seu reino não atinge a dimensão que deseja, toma todas as providências necessárias para que todos os que vivem sob sua proteção fiquem amparados financeira e fisicamente e comete suicídio. A llha do Nevoeiro submerge completamente. Embora a Rainha lute contra as injustiças do mundo, para que as pessoas vivam bem, ela opta por dar cabo a própria vida. Isso se justifica, pois "a utopia romântica de transformar o cotidiano nefasto de pessoas em situação de necessidades, particularmente mulheres, cede lugar ao pessimismo e a angústia - sentimentos também experimentados por pessoas utópicas, que, exatamente, não alcançam satisfação no tempo em que vivem" (Cavalcante, 2007, p. 4).

Segundo Colares (1980), o esquecimento da obra de Freitas pode ser justificado entre vários elementos, dentre estes: "trata-se de um romance que tem base no regional e que parte, de modo inteligentemente programado (embora nem sempre perfeitamente levado a efeito), para os domínios do fantástico" (Colares, 1980, p. 10). Entretanto, não há justificativa plausível para o esquecimento da obra, pois o fantástico ali delineado é o elemento chave na proposição de um mundo novo, a llha do Nevoeiro. Essa sociedade secreta subterrânea é formada por mulheres "que dominam a natureza, a técnica e a ciência, que ocupam cargos e funções com invulgar competência" (Duarte,

${ }^{3}$ A Rainha selecionou Roberta para seu reino, somente por ela que Probo tem acesso a esse mundo subterrâneo. 
2003, p. 19). Conforme aponta Constância Lima Duarte, a llha do Ignoto pode ser entendida como "uma comunidade utópica, regida por leis femininas, que quer se diferenciar da realidade patriarcal, grande responsável pela opressão das mulheres" (Duarte, 2003, p. 19).

Os desejos e projeções dos sujeitos femininos foram fortemente reprimidos pelo sistema patriarcal, seja no âmbito artístico e cultural, seja no político, no qual a mulher não tinha nem mesmo o direito ao voto. Até seu domínio sobre o lar era restrito, pois ela era considerada "inapta para qualquer tipo de governo, como evidenciado pelo pensamento de Fichte, Hegel e Comte" (Santos, 2007, p. 22). Assim, Emília Freitas age contra o patriarcalismo ao criar a llha do Nevoeiro, que "representa por excelência um espaço idealizado e escondido dos olhares, onde apenas mulheres reinavam" (Duarte, 2003, p. 19). A realização feminina só poderia acontecer em um espaço paralelo ao da sociedade oitocentista.

A llha do Nevoeiro, longe de um delírio, configura-se como um espaço criado ficcionalmente para possibilitar uma crítica à sociedade da época, característica principal das obras utópicas, como bem assinala Berriel:

(...) longe de servirem para o escapismo político, as utopias são comumente, retratos irônicos, cáusticos e satíricos da época de seus autores. Adotando a forma de relatos de viagens imaginárias, de tratados e projetos sociais, as utopias foram, em seu meio milênio de história, interlocutoras contínuas das sociedades que as produziram e de suas teorias políticas, sendo muitas vezes ela própria uma teoria e uma proposição política. (Berriel, 2012, p. 25)

Ao remontarmos ao passado, antes mesmo da utopia ser criada como gênero literário, duas obras foram organizadas em um sistema de ideias filosóficas que apontariam possibilidades para melhorar a vida em sociedade. São elas a República (347 a. C.) e as Leis (367 a. C.), de Platão, segundo assinala Teixeira Coelho (1992). Mais tarde, em 1516, Thomas More criou a expressão utopia e inaugurou o gênero literário utópico, que serviu de protótipo para diversos autores criarem ficcionalmente suas sociedades perfeitas. Pela regularidade de ideias que possuem as obras utópicas, encontram-se algumas características recorrentes nesse gênero. Pode-se averiguar em $A$ Rainha do Ignoto, diversas características demonstradas pelo esquema geral organizado 
pelo historiador Raymond Trousson (1979, tradução nossa) sobre a morfologia de uma obra utópica, são algumas delas: o insularismo como condição geográfica e/ou psicológica. De qualquer forma, a utopia é sempre isolada de nossa história. Na obra, a llha do Nevoeiro é totalmente isolada, e ainda escondida por hipnotismo, configurando-se como um não lugar.

A segunda característica que se pode apontar nas obras utópicas, segundo Trousson (1979, tradução nossa), é a autarquia, cuja independência econômica é absoluta. O reino do Ignoto é independente economicamente, sendo autossustentado pelo trabalho coletivo das paladinas. O que levará a uma terceira característica observada pelo autor, o coletivismo, que se dá na ausência de propriedade privada (Trousson, 1979, tradução nossa). Em terceiro lugar tem-se que o utopista professa "desprezo pelo ouro e pela prata", pois teme a desigualdade social (Trousson, 1979, tradução nossa). A Rainha não se preocupava com riquezas, seu dinheiro e bens eram utilizados em benefício da comunidade.

Em seguida encontra-se a "uniformidade social", o utopista é um integrista não aceitando dissensões, oposições, dissidências, reivindicações (Trousson, 1979, tradução nossa). Todas as mulheres da ilha aceitavam sua condição e se sentiam felizes por viver na llha do Nevoeiro, o único que queria revindicar uma condição melhor para ele, e ressentia-se pelo status da Rainha é Probo. Esta personagem não aceitava ser governado por uma mulher.

Outra importante característica a ser mencionada é a religião, reduzida a uma "profissão de fé mínima", ou a "ausência total de religião" (Trousson, 1979, tradução nossa). Não havia nenhum tipo de religião instituída na ilha, nem local próprio para alguma forma de culto, o que se realizava periodicamente eram sessões espíritas, mas sem finalidade doutrinária. Assim, percebe-se que muitas características de $A$ Rainha do Ignoto, de Emília Freitas, podem levar a sua inserção na tradição do romance utópico ocidental.

\section{INTERTEXTUALIDADE E INTERDISCIPLINARIDADE PRESENTES NA OBRA}


O conceito de intertextualidade pode ser entendido de acordo com o "que Bakhtine chama de dialogismo, isto é, as relações que todo enunciado mantém com outros enunciados" (Compagnon, 1999, p. 111). A concepção de dialogismo ainda pode ser relacionada com a compreensão de intertextualidade, segundo Julia Kristeva, "todo texto se constrói como mosaico de citações, todo texto é absorção e transformação de um outro texto" (Kristeva, 1979, p. 68). Assim, o romance de Emília Freitas dialoga intertextualmente com outras obras utópicas.

O folhetim Páginas da História do Brasil escrito no ano de 2000 (186872), de Joaquim Felício dos Santos, foi a primeira obra brasileira a ser considerada uma sátira-utópica (Ribeiro, 2011). Ana Cláudia Romano Ribeiro (2011) menciona que na obra, o Imperador Dom Pedro II faz uma viagem no tempo, através de uma espécie de hipnose realizada por um médium francês, até $\mathrm{o}$ ano de 2000. O Imperador depara-se, 130 anos depois, com o Brasil republicano, em que não há títulos de nobreza, nem privilégios para alguns cidadãos em detrimentos de outros. Quem governa o país é um Presidente que ascendeu do povo. Ele é descendente de uma mãe índia e de um pai negro (descendente de escravos). Da mesma forma, Emília Freitas cria uma obra abolicionista e republicana. Para isso ela dedica vários capítulos que narram à situação dos escravos. Na llha do Nevoeiro eles são abrigados e libertados recebendo condições dignas para sua subsistência.

Segundo Marilena Chauí (2008), as ideias da racionalidade e do poder, nas utopias, levam às ideias de que os homens valem por si mesmos, desconsiderando-se os privilégios de nascimento e sangue, e que as diferenciações entre eles destroem o Estado.

A obra de Freitas explora também a divergência política, mas a transcende ultrapassando os limites dicotômicos, falsamente contraditórios, de república versus monarquia. Embora, "pareça um oxímoro a personagem com o título de 'Rainha' defender ideais abolicionistas e republicanos, essa figura representa um dos muitos disfarces utilizados pela protagonista Diana, para poder lutar contra as injustiças" (Alós, 2005, p. 120). A llha do Nevoeiro é uma monarquia governada por uma mulher que abriga "outras mulheres, crianças 
enjeitas, negros fugidos e trabalhadores" (Alós, 2005, p. 120), auxiliando-os em situações difíceis. Conforme Zélia Maria Viana Pain,

Para os republicanos, o valor político fundamental não se encontra nas qualidades pessoais do governante e sim na liberdade. A liberdade alcançada só pode ser conservada por meio da igualdade, isto é, da justiça. Para os monarquistas o valor político fundamental é a paz. A paz só reinará se houver a ordem, isto é, a lei. O utopista inventa uma sociedade ideal, na qual reinam os valores humanistas: a liberdade e a igualdade, isto é, a justiça e a lei (Pain, 2009, p. 15).

Ao utilizar diversas formas de governo o utopista procura criar um mundo equilibrado, utilizando-se do que há de proveitoso em todas elas. A escolha de Freitas pela ênfase na república justifica-se pelo anseio de liberdade. Anseio por liberdade profissional, política, física, e, principalmente, por liberdade psicológica. Freitas concebe um mundo em que a mulher é completamente livre.

A representação feminina utilizada pela autora está dentro do princípio ético vigente na época. Na trama, uma das principais características para ser uma paladina, é a ética e tudo que ela envolve (civilidade, respeito, caráter, etc.). $\mathrm{O}$ que leva ao segundo conceito observado na obra, a interdisciplinaridade, visto que "a utopia é um gênero literário, de composição mista, pois engloba os campos de reflexão da política, da ética, da religião, etc." (Berriel, 2012, p. 26). Segundo Carvalhal,

\footnotetext{
É o caminho de interdisciplinaridade que nos permite dilatar o campo de ação, (...). Para Remak, os estudos literários comparados incluem "o estudo da literatura além das fronteiras nacionais e linguísticas e qualquer estudo de literatura envolvendo pelo menos dois meios de expressão". Pressupõe, então, as relações entre artes, entre a filosofia, a história e as ciências sociais, as ciências e as religiões (Carvalhal, 2003, p. 45-46).
}

Quando o romance aborda as questões da república e da monarquia, da abolição e da escravatura, pode-se aproximá-la das ciências sociais, mais especificamente da política. Também é possível fazer uma aproximação da obra com a sociologia, quando se observa a presença do suicídio, que dará encerramento a trama. É necessário ressaltar, que embora o romance permaneça dentro do script narrativo do período, sendo o suicídio da personagem feminina muito comum em diversas narrativas, essa escolha 
revela que a Rainha não se submete aos valores sociais, exercendo "seu último poder: o de optar pela não-existência nesse conturbado contexto social" (Alós, 2005, p. 4). Através das concepções de Durkheim (1981), poderíamos afirmar que a protagonista comete suicídio anômalo, conforme explanado por Anselmo Peres Alós,

O suicídio anômalo, por sua vez, acontece quando a ação de autodestruição é movida por não se ter mais perspectivas futuras, como se não houvesse mais como evoluir socialmente. A partir do momento em que o sujeito atinge uma certa posição de poder que the permita não se submeter às regras ditadas pelo social, ele não vê mais motivos para existir socialmente. Tal como suicídio egoísta, ele também decorre de hipertrofia do ego individual frente ao ego social, mas ambos são movidos por razões distintas (Alós, 2005, p. 119).

A Rainha não se adapta ao mundo criado por homens, em que a mulher está presa às convenções estipuladas por leis ilógicas que somente a oprimem. Mas, seu mundo também não atinge as dimensões que ela deseja. Então, ela opta pela única transgressão possível, e a mais radical, o suicídio.

Dessa forma, observa-se a intertextualidade e interdisciplinaridade na obra possibilitando um profícuo diálogo entre textos utópicos e áreas como política, sociologia, história, religião, com a presença do espiritismo em contraposição ao catolicismo. Dentro de um contexto profundamente rico mobilizado em $A$ Rainha do Ignoto não se encontra justificativa para 0 apagamento de tal texto em nossa história literária.

\section{A IMPORTÂNCIA DA VOZ NARRATIVA EM A RAINHA DO IGNOTO}

Outra questão corolária à obra é a escolha da voz narrativa. Na diegese identificamos a presença do típico "narrador-viajante do gênero utópico" (RIBEIRO, 2009, p. 9), Edmundo. Ele simpatiza com os ideais da protagonista e compactua com alguns deles. O que inicialmente era uma atração sentimental transforma-se em admiração pela conduta íntegra da Rainha. Edmundo representa o mediador de dois mundos, o mundo "real" e o mundo "utópico", ao infiltrar-se na Ilha do Nevoeiro. Sua "viagem é um acontecimento 
carregado de dimensão simbólica que permite a ligação e o confronto entre os dois mundos" (Ribeiro, 2011, p. 14).

Edmundo irá ressaltar as características positivas da protagonista, ele que evidenciará o quão bem estruturado é o mundo criado pela Rainha. Mas, esse narrador-viajante mostrará, também, o embate social da lógica patriarcal, e isso dar-se-á através da "metalepse". Esse importante elemento de recurso formal, irá auxiliar na criação de tensão, principalmente quando há desvios para o plano metadiegético (Alós, 2005). Isso acontece a partir do momento que o narrador permite que a personagem Probo continue, temporariamente, a narração. Nesse ponto da narrativa, Probo representa a "voz patriarcal hegemônica" (Alós, 2005, p. 123). Ele critica todas as ações da Rainha e pretende denunciá-la as autoridades, jamais se resignando diante da possibilidade de uma mulher possuir tamanho poder para criar e manter uma comunidade política e financeiramente.

Mas, por que a escolha de uma voz narrativa masculina, em uma obra que evidentemente critica a lógica misógina oitocentista? Justamente por que a voz narrativa masculina possibilitará o contraste entre o mundo masculino e o mundo feminino. O narrador perceberá como algumas atitudes masculinas impedem que as mulheres possam realizar-se profissional e intelectualmente. Ele observará como o estado psicológico delas é muitas vezes afetado por atitudes levianas masculinas levando-as ao enlouquecimento, conforme o seguinte excerto da obra: "[e]sta foi uma moça rica, já entrada na idade, que casou com um moço pobre e peralta. Ele gastou toda a fortuna da desventurada e depois abandonou-a para sempre, e ela enlouqueceu" (Freitas, 2003, p. 202). Percebe-se no romance a dissipação da ideia apregoada durante o final do século XIX sobre a histeria feminina, com base nas concepções de Charcot e posteriormente de Freud, que podem ser percebidas nos romances realistas e naturalistas do período.

Enquanto Probo é a voz patriarcal, Edmundo é a voz mediadora equilibrada pela razão. Quando Edmundo compactua com os ideais da Rainha, ele medeia simbolicamente o mundo feminino e o masculino, demonstrando ser possível uma aproximação de ambos pelo caminho da razão. Percebe-se que a escolha da voz narrativa não só se apresenta como uma estratégia formal para 
denunciar a condição da mulher oitocentista, mas, também, como um meio de aproximar as relações entre o feminino/masculino tão fortemente demarcadas por seus papéis sociais preestabelecidos.

\section{Considerações finais}

Embora a trama pareça relativamente simples, ela rompe com todos os padrões da época, pois a sociedade oitocentista era escravagista e católica. No enredo, a Rainha detém o poder da llha do Nevoeiro, mas sua forma de governar difere da configuração do poder despótico monárquico, pois seus ideais são republicanos. Além disso, ela é abolicionista e kardecista.

Nesse período a mulher não tinha praticamente acesso à leitura, à educação, e era obrigada a casar-se, pois seu sustento e status provinham disso. Até andar livremente pelas ruas Ihes era negado. Na obra, as mulheres estudam, trabalham, viajam pelo país praticando caridades, agem contra comportamentos reprováveis dos homens e utilizam diversas artimanhas para sobreviver numa sociedade marcada pela misoginia. A Rainha nunca se casa, não tem filhos, não está subalterna aos homens, é culta, inteligente e tem poder.

Finalmente, verifica-se que as questões políticas e sociais de tamanha relevância mobilizadas no romance, como a monarquia, a república e a abolição da escravatura, possibilitam a revisão da cultura literária nacional e da autoria feminina. Sabendo-se que,

A cultura literária constitui parte integrante do campo cultural e seu
desenvolvimento foi, até há pouco tempo, regulado e controlado
ideologicamente pela hegemonia patriarcal e seus pressupostos
sobre diferenças assimétricas e hierárquicas de gênero, o que
significa dizer que as mulheres que atuaram, no passado, no campo
das letras, ficaram à margem da literatura, esquecidas e silenciadas
nas histórias literárias. Nesse sentido, uma visada crítica às culturas
literárias nacionais ilumina as conexões entre cultura e poder, entre
instituição intelectual e dominação, entre privilégio e exclusão
(Schmidt; Navarro, 2007, p. 85).

Ao rever $A$ Rainha do Ignoto, percebe-se o quanto é imprescindível o resgate "arqueológico" acerca de um grupo estigmatizado e marginalizado da cultura literária nacional, a autoria feminina. Este resgate permite a redefinição 
do futuro, consoante a justa reivindicação feita através da crítica feminista em "conjugar a literatura e a vida social como uma orquestração de vozes, de forma que somente o diálogo autêntico destas vozes - sem que uma seja normativa e as outras meros desvios - pode subverter o monologismo da voz patriarcal geradora de continuado silêncio e crescente injustiça" (Schmidt; Navarro, 2007, p. 94).

\section{REFERÊNCIAS}

ALÓS, Anselmo Peres. O estranho e a crítica ao patriarcado: resgatando o romance A Rainha do Ignoto, de Emília de Freitas. In: Organon, v. 19, n. 3839, 2005, p. 113-126.

BERRIEL, Carlos Eduardo Ornelas. Meu mundo é outro: literatura utópica nas estantes brasileiras. [entrevista]. Jornal da Unicamp, no 520, março/2012, p. 19-25.

em: <http://www.unicamp.br/ berriel/arquivos/berrielprod3pdf>. Acesso em: 03 out. 2014.

\begin{tabular}{ccccc}
\multicolumn{4}{c}{. Proposta de criação do U-TOPOS - Centro de Estudos sobre utopia } \\
IEL & - & Unicamp, & 2008. & Disponível
\end{tabular} $<$ http://www.iel.unicamp.br/pesquisa/arquivos/Centro de Pesquisa sobre Utopia U-TOPOS.pdf>. Acesso em: 03 out. 2014.

CARVALHAL, Tania. 0 próprio e o alheio: ensaios de literatura comparada. São Leopoldo: UNISINOS, 2003.

CAVALCANTE, Alcilene. A representação feminina em A Rainha do Ignoto, de Emília Freitas. In: Anais do XII Seminário Nacional e III Seminário Internacional Mulher e Gênero, Identidade e Hibridismo Cultural. Ilhéus: UESC, 2007, $\quad$ p. 1-6. Disponível em: <http://www.esc.br/seminariomulher/anais/PDF/Mesas/ALCILENE\%2 OCAVALCANTE.pdf>. Acesso em: 04 out. 2014.

CHAUÍ, Marilena. Notas sobre a utopia. In: Ciência e Cultura. SBPC, v. 60, no spe 1, julho 2008, p. 7-12. Disponível em: <http://cienciaecultura.bvs.br/scielo.p hp?pid=S000967252008000500003\&script=sci arttext> Acesso em: 03 out. 2014.

COELHO, Teixeira. O que é utopia. São Paulo: Abril Cultural/Brasiliense, 1985.

COLARES, Otacílio (Org.). Do romântico regional ao fantástico. In: FREITAS, Emília. A Rainha do Ignoto: um romance psicológico. 2. ed. Fortaleza: Imprensa Oficial do Ceará, 1980.

COMPAGNON, Antoine. 0 demônio da teoria: literatura e senso comum. Tradução de Cleonice Paes Barreto Mourão. Belo Horizonte: UFMG, 1999.

DUARTE, Constância Lima. O cânone e a autoria feminina. In: SCHMIDT, Rita Terezinha (Org.). Mulheres e literatura: (trans)formando identidades. Porto Alegre, 1997, p. 53-60. 
A Rainha do Ignoto ou a impossibilidade da utopia. In: FREITAS, Emília. A Rainha do Ignoto. Atualização do texto, introdução e notas: Constância Lima Duarte. 3. ed. Florianópolis/Santa Cruz do Sul: Mulheres/ EDUNISC, 2003.

FREITAS, Emília. A Rainha do Ignoto. Atualização do texto, introdução e notas: Constância Lima Duarte. 3. ed. Florianópolis/Santa Cruz do Sul: Mulheres/ EDUNISC, 2003.

A Rainha do Ignoto. Pesquisa, organização, atualização ortográfica, apresentação crítica e notas: Otacílio Colares. 2. ed. Fortaleza: Imprensa Oficial do Ceará, 1980.

KRISTEVA, Julia. Introdução à semanálise. São Paulo: Perspectiva, 1979.

LOGAN, George M.; ADAMS, Robert M. (Org.). Introdução. In: MORE, Thomas. Utopia. Tradução Jefferson Luis Camargo, Marcelo Brandão Cipolla. 3. ed. São Paulo: WMF Martins Fontes, 2009. p. XV-XLVII.

MORE, Thomas. Utopia. Organização George M. Logan, Robert M. Adams. Tradução Jefferson Luis Camargo, Marcelo Brandão Cipolla. 3. ed. São Paulo: WMF Martins Fontes, 2009. p. XV-XLVII.

PAIM, Zélia Marta Vianna. O movimento dos sentidos: de utopia à conversão. 225 f. Tese (Doutorado em Letras) - Universidade Federal de Santa Maria, Santa Maria, 2009.

RIBEIRO, Ana Cláudia Romano. Instâncias mediadoras do relato de viagem imaginária a uma terra utópica: o prefácio e o narrador-editor de La Terre Australe connue (1676), de Gabriel Foigny. Caos em revista. Revista.doc, n. 7, jan.-jul/2009, $\quad$ p. $\quad 7-22 . \quad$ Disponível em $<$ http://www.revistapontodoc.com/7anacr.pdf>. Acesso em: 07 out. 2014.

Sátira, utopia e ficção científica em 'A história do Brasil escrita pelo Dr. Jeremias no ano de 2862' e 'Páginas da' História do Brasil, 'escritas no ano 2000', de Joaquim Felício dos Santos. Recorte Revista Eletrônica, n. 2, 2011, p. 1-19. Disponível em: <http://revistas.unincor.br/index.php/recorte/article/view/343>. Acesso em: 07 out. 2014.

SANTOS, Salete Rosa Pezzi dos. Representação do feminino em uma escritura desautorizada: Celeste, de Maria Benedita Câmara Bormann e $O$ Perdão de Andradina América de Oliveira. 222 f. Tese (Doutorado em Literatura Comparada) - Universidade Federal do Rio Grande do Sul, Porto Alegre, 2007.

SCHMIDT, Rita Terezinha; Navarro, Márcia Hoppe. A questão de gênero: ideologia e exclusão. Anais do 2 o Congresso Internacional sobre Mulher, Gênero e Relações de Trabalho. Goiânia: UFG, 2007, p. 85-96.

SILVA, Alexander Meireles da. Utopia para quem? O desenvolvimento da literatura de utopia feminina. Revista Eletrônica do Instituto de Humanidades, vol. VI, no XXI, abril-junho/2007, p 1-14.

TROUSSON, Raymond. Voyages aux pays de nulle part: histoire literaire de la pensée utopique. Bruxelles: l'Université de Bruxelles, 1979. 